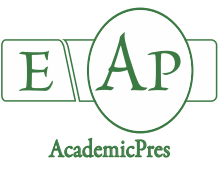

Zhang Z et al. (2020)

Notulae Botanicae Horti Agrobotanici Cluj-Napoca 48(1):378-387

DOI: $10.15835 /$ nbha48111779

Research Article

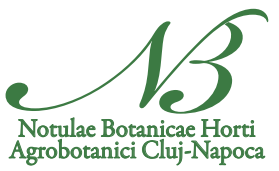

\title{
Capture of Aphis gossypii Glover (Homoptera: Aphididae) during explosion in a cotton field in response to height and orientation of yellow sticky cards
}

\author{
Ze ZHANG ${ }^{\text {la }}$, Xiaodong SHI ${ }^{1 \mathrm{~b}}$, Guolong $\mathrm{ZHANG}^{2}$, Lulu MA ${ }^{1}$, \\ Qiang $Z \mathrm{HANG}^{1}$, Jiao $\mathrm{LIN}^{1}$, Xin $\mathrm{LV}^{1 *}$
}

\author{
${ }^{I}$ Shibezi University, College of Agriculture, The Key Laboratory of Oasis Ecology Agricultural, Xinjiang Production and Construction \\ Group, Shihezi 832003, China; zhangze1227@shzu.edu.cn; lxshz@126.com (*orresponding author) \\ ${ }^{2}$ Cansu Wuwei National Agricultural Sci-Tech Park, Gansu Province, China; zgl404253760@qq.com \\ ${ }^{a, b}$ These authors contributed equally to the work
}

\begin{abstract}
Aphis gossypii Glover is a polyphagous herbivore that causes serious damage to cottons. Current understanding to trap its population is limited in the field approach. In this study, a two-year-course study was conducted to test the yellow sticky card (YSC) effects of orientation (east, up, west, and bottom) and height (30, 60, and $90 \mathrm{~cm}$ over the cotton crown) on numbers of trapped $A$. gossypii every three days in ninth days after explosion in a cotton plantation in Shihezi, Xinjiang, Northwest China in 2014 and 2015. In 2014, YSCs in the east orientation at a height of $60 \mathrm{~cm}$ trapped the highest number of $A$. gossypii five days after explosion. In 2015, highest number of $A$. gossypii were trapped by YSCs in the up orientation at a height of $30 \mathrm{~cm}$. Our results showed that YSC in the up orientation at $30-60 \mathrm{~cm}$ over the cotton crown can trap the highest number of $A$. gossypii since the five to seven days after aphid explosion. In conclusion, the spatial placement of sticky cards can be available to trap the maximum number of pests which should be incorporated into observations in continuous years.
\end{abstract}

Keywords: abundance; across-year investigation; cotton field; natural control; pest management tactic

\section{Introduction}

Aphis gossypii glover (Homoptera: Aphididae) is a poly phagous herbivore that causes serious damage to many crops (Parajulee, 2007). In 1854, this aphid was first reported to impair cotton yield in South Carolina, USA (Paddock, 1919). Its feeding behavior was recorded in tropical, subtropical, and temperate agricultural systems (Inaizumi, 1980; Kocourek et al., 1994). Recently, it was also found that A. gossypii can cause damage to plants of cucumber (Cucumis sativus Linn) (Darvishzadeh and Jafari, 2016), okra (Abelmoschus spp.) (Abang et al., 2016), and cotton (Gossypium herbaceum) (Gao et al., 2016). Due to the significant impact on cotton growth and yield, this pest was also named as cotton aphid (CA) (Steinkraus et al., 2002; Gao et al., 2016; Wang et al., 2016). 
CA causes damage either directly by feeding, which results in curling and deformation of young leaves and stems, or indirectly by contaminating the leaves and fruits with honeydew, which favors the growth of black sooty mold that inhibits photosynthesis and causes substantial yield loss (Capinera, 2000; Abang et al., 2016). The honeydew attracts ants that can fend off natural enemies of aphids (Yokomi and Tang, 1995). In addition, CA is known to transmit more than 50 plant viruses (Blackman Eastop, 2007). Although chemical pesticide is usually used to control CA the effect is usually not desired enough because of these multiple impacts by cotton aphid and their resistance to chemical treatment (Owusu and Yeboah, 2007).

In temperate regions, CA can survive and spread over rigorous winters as a holocyclic life pattern allows it to alternate between primary and secondary hosts. The primary hosts for CA are typically woody plants. For example, in hibiscus CA migrates and conducts sexual reproduction during autumn while the secondary hosts are usually herbaceous plants, where CA will undergo asexual reproduction (parthenogenesis) to produce numerous offspring (Wang et al., 2016). CA hatches from eggs on winter hosts beginning in March and reproduces for two to three generations before alate adults migrate to the next hosts from late April to midMay. CA has a broad host spectrum with a range of almost 700 host plants worldwide (Capinera, 2000). Hence, it is impossible to detect or control the explosion of CA at its hosting stage of the life cycle.

Trapping field populations of insects is an important precondition to cope with pest explosion. Yellow stick card (YSC) has been employed as a trap for detecting and monitoring field pests since the 1920s (Lloyd, 1921). Thereafter, YSC has been proven to be available to trap several species of whiteflies, aphids, and fungus gnats (Steinkraus et al., 2002; Chu et al., 2004; Beers, 2012; Bian et al., 2016). Height and orientation are critical for the use of YSC to produce efficient trapping. This was because pests naturally perceive sunlight as the direction of their flying route and adjustment (Al-Jabr and Cranshaw, 2007). Height and orientation of trapping cards are two necessary parameters for the design to trap the maximum number of pests in a regional space (Amoah et al., 2017). For example, the vertical/trunk trap caught the highest numbers of adult Aphelinus mali (Hymenoptera: Aphelinidae) (Beers, 2012). In another report, the combination of a 0-20 cm height above the canopy in an east-west orientation was found to be effective in trapping the yellow tea thrips (Scirtothrips dorsalis Hood) (Bian et al., 2016). Another factor that may determine the number of trapped pests is the time after explosion combined with special placement. According to Kerns et al. (2015), the economic injury levels of CA in cotton fields was on average 137 units per leaf approximately a week after the explosion with mean population doubled, and economic thresholds were calculated to decline during the week time before significant economic injury occurs. Therein, every three days in the first week after the explosion were chosen for management tactic. The specific combination of height and orientation on these days have not been fully detected for monitoring the abundance of CA.

In this study, to better develop the management tactic for the control of CA damage on cotton, we sought to elucidate the combinations of height and orientation of the YSC trap and monitor the trapped numbers of CA in the first week after the explosion. A two-year experiment in 2014 and 2015 was conducted to investigate trapping effects. We compared dynamic results within each year and between the two years with the aim to obtain scientific records for the application of our data as a reference.

\section{Materials and Methods}

\section{Study site and experiment design}

This study was conducted at cotton study and production center in National Science \& Technology Park for Agriculture in Xinjiang ( $44^{\circ} 21^{\prime}$ N, $86^{\circ} 1^{\prime}$ E), Beiquan, Shihezi, Xinjiang, North-West China (Figure 1). The total area of the local cotton field was 8 ha with an elevation of $433-437 \mathrm{~m}$ and a slope of $6 \%$. The cotton for the study was employed with the cultivar 'Xinlu Early No. 45' which was interplanted with the cultivar 'Xinlu Early No. 62'. The study was conducted as a split-plot design with a total area of $1840 \mathrm{~m}^{2}(80 \mathrm{~m}$ 
$\times 23 \mathrm{~m}$ ). The main plots were set at three heights for YSC $3 \mathrm{~cm}, 6 \mathrm{~cm}$, and $9 \mathrm{~cm}$ above the top of the cotton crown and each was replicated three times (Figure 1). YSC was nailed at different heights to a pole that was fixed deep within the field. YSC was framed by iron sticks to avoid being interrupted by the wind. All main plots were randomly placed to fully eliminate the effect between random factors and block placement. Each main plot was divided into nine randomly placed plots separated by barriers with a width of $2.5 \mathrm{~m}$ between adjacent plots leaving each plot with an area of $150 \mathrm{~m}^{2}(25 \mathrm{~m} \times 6 \mathrm{~m})$. Within each main plot were divided four sub-plots wherein four YSCs were fastened in four orientations with the sticky surface toward the west, east, up, and down directions. Thereafter, YSCs in each sub-plot can trap CAs in an area of $37.5 \mathrm{~m}^{2}(12.5 \mathrm{~m} \times 3 \mathrm{~m})$. The plots were designed in 2014 and investigated for both 2014 and 2015.

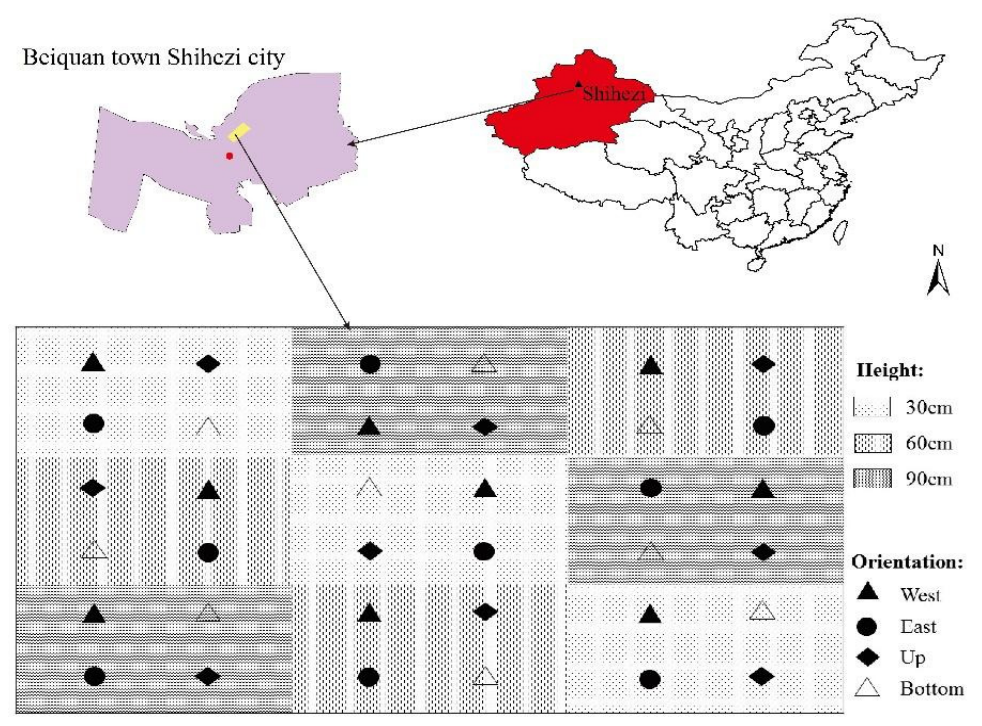

Figure 1. Study location in Xinjiang, China and the layout of experiment design

\section{The manufacture of YSC}

YSCs in this study were manually manufactured using a piece of aluminum-plastic card (area: $900 \mathrm{~cm}^{2}$, $30 \mathrm{~cm} \times 30 \mathrm{~cm}$ ) adhered to a wooden board (length $\times$ width $\times$ thickness, $30 \mathrm{~cm} \times 30 \mathrm{~cm} \times 5 \mathrm{~cm}$ ). The yellow color can be described as values of red (R), green (G), and blue (B) combination as a color-code combination of 255-255-0 (Color-Hex 2019). Although artificial adjustment of color can have some effect on the growth and physiology of plants, the effect of yellow coloration is rare (Wei et al., 2020; Ying et al., 2020). The yellowcolored surface was brushed with sticky insect glue (Zhinian, Hot Melt Adhesive Ltd., Dongguan, Guangdong, China) and the opposite surface was connected to a wooden stick (A-stick) (length $\times$ width $\times$ thickness, $50 \mathrm{~cm}$ $\times 5 \mathrm{~cm} \times 5 \mathrm{~cm}$ ) by the frame of two angle-irons. Subsequently, A-stick was nailed to another two wooden sticks (B-stick) (length $\times$ width $\times$ thickness, $200 \mathrm{~cm} \times 5 \mathrm{~cm} \times 5 \mathrm{~cm}$ ) which were inserted into the ground at a depth of at least $50 \mathrm{~cm}$. During the study, both A and B-sticks were adjusted for its height above ground to maintain the height of YSC above a certain height from the cotton crown.

\section{Experimental process}

Cotton seeds were first sown on 26 April 2014, and re-sown on 28 May 2015, to avoid spring frost. Nitrogen $(\mathrm{N})$, phosphorus $(\mathrm{P})$, and potassium $(\mathrm{K})$ are all necessary elements for cotton which are used in fertilizers in this study. Before sowing, soils were fed by mixed fertilizers of triple superphosphate $\left(\mathrm{N}-\mathrm{P}_{2} \mathrm{O}_{5}-\right.$ $\left.\mathrm{K}_{2} \mathrm{O}, 0-46-0\right)$ at a rate of $135 \mathrm{~kg} \mathrm{ha}^{-1}$ and potassium sulfate $\left(\mathrm{N}-\mathrm{P}_{2} \mathrm{O}_{5}-\mathrm{K}_{2} \mathrm{O}, 0-0-51\right)$ at a rate of $90 \mathrm{~kg} \mathrm{ha}^{-1}$. Nitrogen fertilizers were delivered using urea $\left(\mathrm{N}-\mathrm{P}_{2} \mathrm{O}_{5}-\mathrm{K}_{2} \mathrm{O}, 46-0-0\right)$ at a rate of $75 \mathrm{~kg} \mathrm{ha}^{-1}$ one week after first sowing and at a rate of $175 \mathrm{~kg} \mathrm{ha}^{-1}$ during boll growth. All cotton crops were planted along an east-west gradient 
with drip irrigation to lateral beds possessing a width of about $2 \mathrm{~m}$. Planting lined beds were spaced with alternative $10 \mathrm{~cm}$ and $66 \mathrm{~cm}$ and rows were spaced at $10.5 \mathrm{~cm}$. Weeds were controlled during germination and two rounds of inter-tillage were made at flowering and boll-generation stages. The number of trapped CAs was recorded every two days in the first week after the explosion. In 2014, CA numbers were recorded on 28 May, 30 May, 1 June, 3 June, and 5 June; in 2015, records were made at 2, 4, 6, 8 and 10 July. The general CA explosion was delayed in 2015 compared to 2014 due to spring frost and heavy rains during germination (Wang et al., 2015). The number of CAs was calculated by eye for every YSC. Other aphids and the predators were excluded from counting the number of CAs.

\section{Statistical analysis}

Both tests of normality and homogeneity of variance were checked for the number of trapped CA and no data transformations were necessary. Mixed-model ANOVA was conducted on interactive effects of YSC height and orientation with repeated measures every two days in the first week after the CA explosion in both years $(n=3)$. When a significant effect was indicated at 0.05 level, results about trapped CA numbers were ranged with the LSD test $(\alpha=0.05)$. Dynamic results between two years were compared across all treatments of YSC height and orientation $(n=36)$ to reveal the general dynamics in two years. Under the condition when combined effects of YSC height and orientation were significant for trapped CA numbers across days after the explosion $(n=15)$, a third ANOVA was conducted repeatedly for data in 2014 and 2015. Subsequently, data between 2014 and 2015 were correlated across combined treatments $(n=12)$, investigating days $(n=5)$, and combined treatments and days $(n=60)$ to confirm the similarity of data trends between two years. ANOVA and multiple comparisons for means were conducted based on the General Linear Model (GLM) and MEAN procedures using SAS (SAS Institute Inc., NC, USA), respectively. Correlations were firstly analyzed by Spearman using Proc CORR of SAS. When the significance was indicated data were fit by a suitable curve with a determination coefficient using SigmaPlot v12.0 (Systat Software, Inc., San Jose, CA, USA).

\section{Results}

Number of trapped CA in 2014 and 2015

Interactive effects of YSC height and orientation were significant to the number of trapped CA in all five days after the explosion in both 2014 and 2015 (Table 1). In 2014, YSCs in the east orientation at height of $60 \mathrm{~cm}$ resulted in the highest number of trapped CAs in all five days after the explosion, whose results were not significantly different with that in the up orientation at height of $30 \mathrm{~cm}$ in the third day and that in the up orientation at height of $60 \mathrm{~cm}$ in the fifth, seventh, and ninth day (Figure 2 left). In contrast, YSCs in the bottom orientation at heights of $30 \mathrm{~cm}, 60 \mathrm{~cm}$, and $90 \mathrm{~cm}$ all resulted in the fewest trapped CAs since the third day after the explosion. On the first day after the explosion in 2015, the number of trapped CAs was the highest on YSCs in the up orientation at heights of $60 \mathrm{~cm}$ and $90 \mathrm{~cm}$ (Figure 2F). Thereafter, since the third day on the highest number was replaced by the treatment of the up orientation at a height of $30 \mathrm{~cm}$. YSCs in the bottom orientation at heights of $30 \mathrm{~cm}, 60 \mathrm{~cm}$, and $90 \mathrm{~cm}$ trapped the fewest CAs throughout the investigating period (Figure 2 right).

\section{Number of trapped CA between 2014 and 2015}

The total number of trapped CAs across treatments generally increased as the number of days increased after the explosion and was higher in 2015 than in 2014 (Figure 3). In 2014, the number of trapped CAs significantly increased since the fifth day after the explosion and in the ninth day was 27 times higher than in on the first day $(F=34.39 ; P<0.0001)$. In 2015, the increment of trapped-CA numbers was not significant until 
382

the seventh day after the explosion, and on the ninth day was 3 times higher than on the first day $(F=50.79$; $P<0.0001)$. Generally, the number of trapped CAs was four times higher in 2015 than in 2014.

In 2014, the highest number of CAs was trapped by YSCs in the east and up orientations at a height of $60 \mathrm{~cm}(F=5.01 ; P<0.0001)$ (Figure 4A). YSCs in the bottom orientation at $30 \mathrm{~cm}, 60 \mathrm{~cm}$, and $90 \mathrm{~cm}$ trapped fewest CAs. In 2015, YSCs in the up orientation at heights of $30 \mathrm{~cm}, 60 \mathrm{~cm}$, and $90 \mathrm{~cm}$ trapped highest number of CAs, followed by those in the west orientation at three heights (Figure 4B).

Table 1. $F$ values from ANOVA analysis of height $(\mathrm{H})$, direction $(\mathrm{D})$ and their interaction $(\mathrm{H} \times \mathrm{D})$ on number of trapped aphids in $1^{\text {st }}, 3^{\text {rd }}, 5^{\text {th }}, 7^{\text {th }}$ and $9^{\text {th }}$ day after aphid explosion in 2014 and 2015

\begin{tabular}{|c|c|c|c|c|c|}
\hline \multirow{2}{*}{ Source of variation } & \multicolumn{5}{|c|}{ Days after aphid explosion } \\
\cline { 2 - 6 } & 1 & 3 & 5 & 7 & 9 \\
\hline 2014 & & & & & $728.84^{* * *}$ \\
\hline $\mathrm{H}$ & $58.43^{* * *}$ & $67.96^{* * *}$ & $250.19^{* * *}$ & $315.83^{* * *}$ & $1517.98^{* * *}$ \\
\hline $\mathrm{D}$ & $66.46^{* * *}$ & $57.53^{* * *}$ & $439.00^{* * *}$ & $1029.26^{* * *}$ & $171.35^{* * *}$ \\
\hline $\mathrm{H} \times \mathrm{D}$ & $68.51^{* * * *}$ & $25.20^{* * *}$ & $40.43^{* * *}$ & $67.22^{* * *}$ & \\
\hline 2015 & & & & & $695.54^{* * *}$ \\
\hline $\mathrm{H}$ & $57.63^{* * *}$ & $20.34^{* * *}$ & $27.19^{* * *}$ & $177.63^{* * *}$ & $6542.21^{* * *}$ \\
\hline $\mathrm{D}$ & $1099.34^{* * *}$ & $1425.47^{* * *}$ & $1648.17^{* * *}$ & $2904.94^{* * *}$ & $614.24^{* * *}$ \\
\hline $\mathrm{H} \times \mathrm{D}$ & $15.35^{* * *}$ & $15.52^{* * *}$ & $24.02^{* * *}$ & $75.39^{* * *}$ & 214 \\
\hline
\end{tabular}

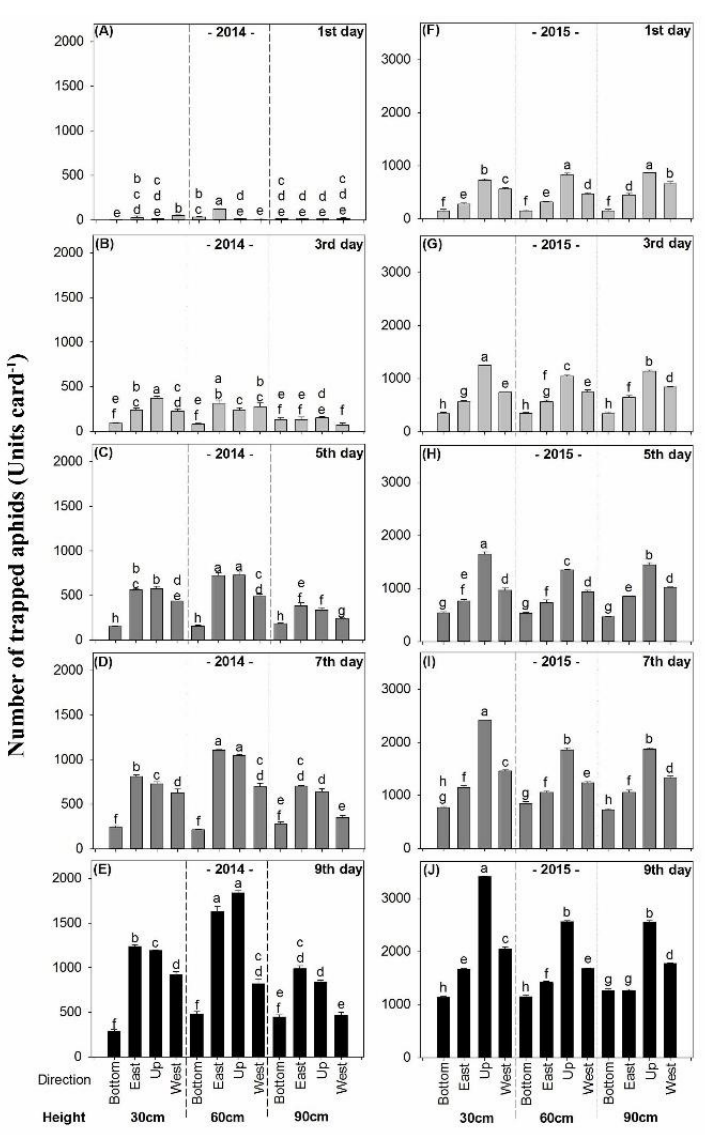

Figure 2. Number of trapped CA by YSCs in orientations of east, west, up, and bottom at heights of 30 $\mathrm{cm}, 60 \mathrm{~cm}$, and $90 \mathrm{~cm}$ one, three, five, seven, and nine days after explosion in both 2014 (left) and 2015 (right). Different letters in a given day indicate significant results according to LSD test at 0.05 level 


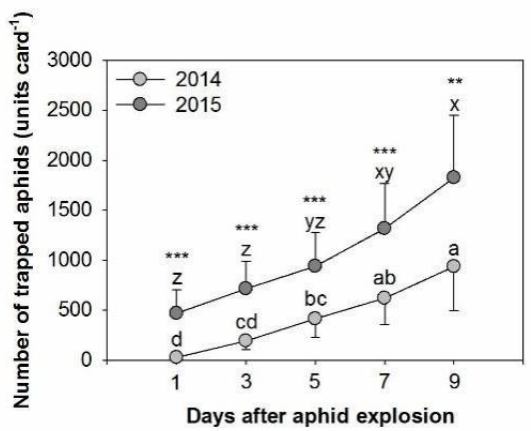

Figure 3. Number of trapped CA in one, three, five, seven, and nine days after explosion in both 2014 (bottom) and 2015 (up). Different letters indicate significant difference among days in the year of 2014 or 2015. Letters of $x, y$ and $z$ demonstrate for data in 2015; letters of $a, b, c$ and d demonstrate for data in 2014. Asterisks indicate significant difference at a given day between 2014 and 2015. ${ }^{* *}, P<0.05$; $^{* * *}$, $P<0.01$

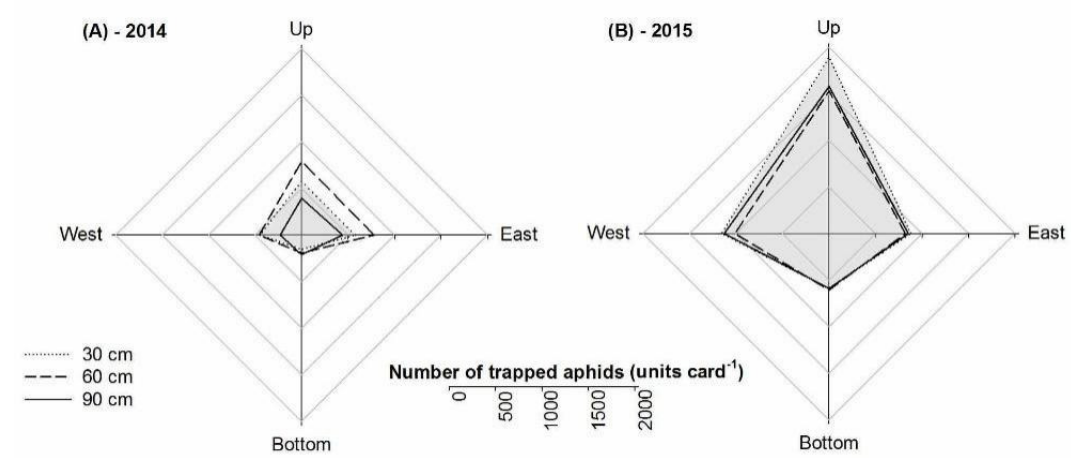

Figure 4. Number of trapped CA by YSCs in orientations of east, up, west, and bottom at heights of $30 \mathrm{~cm}, 60$ $\mathrm{cm}$, and $90 \mathrm{~cm}$ in 2014 (A) and 2015 (B). The radar area of data at height of $30 \mathrm{~cm}$ was filled with the color of light gray

\section{Correlation analysis}

No correlation was indicated between the number of trapped CAs in 2014 and 2015 when data were calculated across height and orientation treatments (Table 2). However, a significant correlation was indicated by the Spearman function across height, orientation, and number of days (Figure 5).

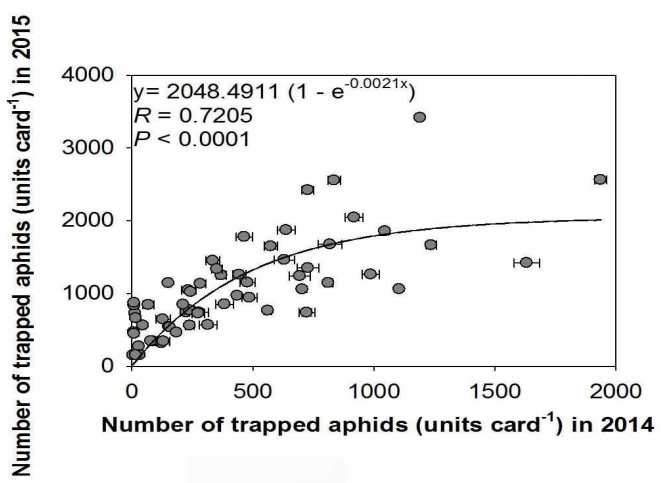

Figure 5. Correlation between numbers of trapped CAs in 2014 and 2015 using data cross combined parameters of height, orientation, and days 
Table 2. Correlation analysis between numbers of tapped aphids in 2014 and in 2015 across different data sets according to Pearson and Spearman functions

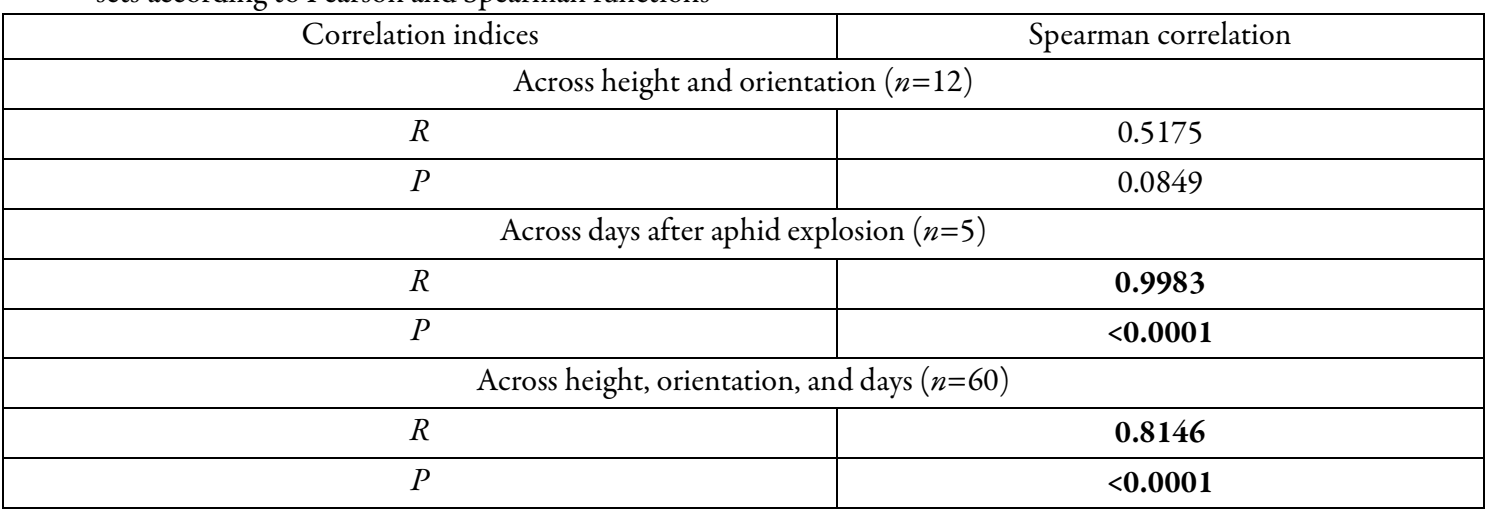

\section{Discussion}

Records revealed that CA is a prevalent pest in Xinjiang, with frequent outbreaks in 1991, 1992, 1994 , 1995, 1999, 2000, 2001, 2004, etc. (Wu and Guo, 2003; Li et al., 2008). This historical data shows that the abundance of CA increased from June to July in Xinjiang. In early mid-June the number of CAs was reported to persist, increasing in 2011 and 2013 when the abundance of another cotton aphid (Acyrthosiphon gossypii Mordvilko) had declined (Gao et al., 2016). The increasing number of CAs was also reflected by our results, according to the number of trapped CAs by YSC. Higher number of trapped CAs in 2015 can be attributed to multiple factors, but temperature may account for a large part of all explanations (Wang et al., 2015). Although the spring of 2014 went by with ordinary precipitation in our study region, the daily highest temperatures in May prior to our study time reached $30^{\circ} \mathrm{C}$ (Shihezi Meteorological Bureau) which has been proven to reduce adult survival and reproduction (Gao et al., 2016).

Because the number of trapped CAs increased since the fifth and seventh days after the explosion in 2014 and 2015, respectively, dynamic results of trapped-CA numbers can be grouped by different intervals in different years. In 2014, since the fifth day after explosion trapped-CA number significantly increased in the up orientation at a height of $60 \mathrm{~cm}$. This combined treatment also resulted in the highest number of trappedCAs on the first day after the explosion and the second highest number from the seventh day in 2015 . In addition, the combination of the east orientation at height of $60 \mathrm{~cm}$ and that of the upper orientation at a height of $30 \mathrm{~cm}$ also resulted in the highest number of trapped CAs in 2014 and 2015, respectively. The height of 30-60 cm and the up orientation may be aphids' preferred flight height and visual perception (Byers, 2011). The high number of trapped CAs by YSCs in the east orientation in 2014 may be due to east-gal and east-gust events at the speed of $1.9 \mathrm{~m} \mathrm{~s}^{-1}$ in Shihezi (Shihezi Meteorological Bureau) driving the aphid population towards YSCs.

General results of combined treatments of height and orientation across days also indicated that most CAs were trapped on top of YSCs, while the fewest of them were captured on the bottom side. This was reasonable because the top orientation was more effective in reflecting the yellow color than the bottom one. In addition to visual perception of aphids (Byers, 2011), upper orientation can match higher probability of aphid landing even in winds (Storer et al., 1999). Generally, our results indicated that YSCs at heights between $30 \mathrm{~cm}$ and $60 \mathrm{~cm}$ can trap more CAs than those in $90 \mathrm{~cm}$. These results were different from that in Straw et al. (2011) where the highest numbers of alate Elatobium abietinum Walker (Hemiptera: Aphididae) were 9-17 $\mathrm{cm}$ above the ground at Sitka spruce plantations. However, our results can be comparable with those in Bian $e t$ al. (2016) where more thrips were trapped at 0-20 cm above the tea canopy. The proper height of trapping 
aphids can be determined by the height of the plant canopy. Thus, a height of $60 \mathrm{~cm}$ above canopy is recommended in this study.

Interestingly, numbers of trapped CAs cannot be correlated to each other between 2014 and 2015 across data with combined treatments of height and orientation unless data from dynamic days were involved (Table 2; Figure 5). These results suggested that the occurrence and distribution of trapped CAs were quite heterogeneous between years and different in 2014 from those in 2015 if no time factor was involved. Our results can be directly supported by data from Shrestha and Parajulee (2013) and Gao et al. (2016), where CA populations were found to be correlated to each other between 2002 and 2003 (Spearman: $n=17, R=0.6538$, $P=0.0044$ ) and between 2011 and 2013 (Spearman: $n=11, R=0.8863, P<0.0001$ ). In contrast, data from Brown \& Myers (2010) regarding aphid infestation rate on 24 orchards in 2007 and 2008 without any dynamic time factors indicated no correlation calculated by either Pearson $(n=24, R=-0.2522, P=0.2344)$ or Spearman functions ( $n=24, R=-0.1895, P=0.3753$ ). Regarding that many field studies on aphids have been re-checked for at least one more year, multiple-year data is therefore suggested to be investigated with dynamic monitoring so as to minimize the heterogeneous effect on data in a specific year.

\section{Conclusions}

Using the yellow sticky card (YSC) to trap Aphis gossypii individuals in a cotton field, a placement at the height between 30 and $60 \mathrm{~cm}$ above the canopy towards the up orientation was recommended to achieve the highest number of the pest population. With regard to the statistical difference, the eastern orientation would also be a possible arrangement of YSC at the height of $60 \mathrm{~cm}$ to trap the most $A$. gossypii. All data was obtained from field observations in the years 2014 and 2015, which may suffer from uncertain data variation caused by climate, phenology, and sudden anthropogenic interrupts. However, the maximum number of $A$. gossypii is estimated to be around 2,000 per card, which would supply theoretical evidence for further design.

\section{Acknowledgements}

This research was supported by the project of Special fund project of central leading local science and technology development (grant number 2019BT0826 ) and Key Scientific and technological project of the Xinjiang Production and Construction Crop (grant number 2018AA004).

\section{Conflict of Interests}

The authors declare that there are no conflicts of interest related to this article.

\section{References}

Abang AF, Srinivasan R, Kekeunou S, Yeboah M, Hanna R, Lin MY, ... Bilong Bilong CF (2016). Relationship of phenotypic structure and allelochemical compounds of okra (Abelmoschus spp.) to resistance against Aphis gossypii glover. International Journal of Pest Management 62(1):55-63.

Al-Jabr AM, Cranshaw WS (2007). Trapping tomato psyllid, Bactericera cockerlli (Sulc) (Hemiptera:Psyllidae), in greenhouses. Southwestern Entomologist 32(1):25-30. 
Amoah B, Schilling MW, Phillips TW (2017). Physical factors influencing orientation of Tyrophagus putrescentiae (Schrank) (Sarcoptiformes: Acaridae) to food-baited traps. Journal of Insect Behavior 30(5):544-562.

Beers EH (2012). Effect of trap color and orientation on the capture of Aphelinus mali (Hymenoptera:Aphelinidae), a parasitoid of woolly apple aphid (Hemiptera: Aphididae). Journal of Economic Entomology 105(4):1342-1349.

Bian L, Yang PX, Yao YJ, Luo ZX, Cai XM, Chen ZM (2016). Effect of trap color, height, and orientation on the capture of yellow and stick tea thrips (Thysanoptera: Thripidae) and nontarget insects in tea gardens. Journal of Economic Entomology 1:1-8.

Blackman RL, Eastop VF (2007). Taxonomic issues. In: van Emden HF, Harrington R (Eds). Aphids as crop pests. Oxfordshire (UK): CAB International, pp 1-29.

Brown A, Myers JH (2010). Temporal and spatial variability of rosy apple aphid Deysaphis plantaginea populations: is there a role of the alternate host plant Plantago major? Agriculture and Forest Entomology 12(4):333-341.

Byers JA (2011). Analysis of vertical distributions and effective flight layers of insects: Three-dimensional simulation of flying insects and catch at trap heights. Environmental Entomology 40:1210-1222.

Capinera JL (2000). Melon aphid or cotton aphid, Aphis gossypii Glover (Insecta: Hemiptera: Aphididae). EENY-173 (IN330), one of a series of the Entomology and Nematology Department (Cooperative Extensino Service, Institute of Food and Agricultural Sciences) University of Florida. Available from: bttp://edis.ifas.ufl.edu/in330

Chu CC, Simmons AM, Chen TY, Alexander PJ, Henneberry TJ (2004). Lime green light-emitting diode equipped yellow sticky card traps for monitoring whiteflies, aphids and fungus gnats in greenhouses. Insect Science 11(2):125-133.

Color-Hex (2019). The color-hex color names. Retrieved 2019 January 31 from $h$ ttp://www.color-hex.com/color-names.html

Darvishzadeh S, Jafari S (2016). Life history performance of Aphis gossypii Glover (Aphididae) on seven cucumber cultivars. International Journal of Pest Management 62:245-250.

Gao GZ, Ponsard S, Lu ZZ, Wang PL, Sharma S (2016). Different thermal responses in two coexisting aphids may account for differences in their seasonal abundance in cotton fields. International Journal of Pest Management 62:288-294.

Inaizumi M (1980). Studies on the life-cycle and polymorphism of Aphis gossypii Glover (Homoptera:Aphididae) [Aphid]. Special Bulletin of the College of Agriculture-Utsunomiya University (Japan).

Li HB, Wu KM, Xu Y, Yang XR, Yao J, Sun SL, Li XY, Jiang HY (2008). Dynamic analysis of population of cotton aphids in the south of Xinjiang. Xinjiang Agricultural Science 45:670-675.

Lloyd L (1921). Notes on a colour tropism of Asterichiton (Aleurodes) vaporariorum, Westwood. Bulletin of Entomological Research 12(3):355-359.

Kocourek F, Havelka J, Bberankova J, Jarosiik V (1994). Effect of temperature on development rate and intrinsic rate of increase of Aphis gossypii reared on greenhouse cucumbers. Entomologia Experimentalis et Applicata 71:59-64.

Owusu E, Yeboah PM (2007). Status of cotton aphid, Aphis gosypii Glover (Homoptera: Aphididae) resistance to insecticides in Southern Ghana. Ghana Journal of Science 47:107-115.

Paddock EM (1919). The cotton or melon louse: life history studies. Texas AES. Bulletin 257:1-54.

Parajulee MN (2007). Influence of constant temperature on life history parameters of the cotton aphid, Aphis gossypii, infesting cotton. Environmental Entomology 36:666-672.

Shrestha RB, Parajulee MN (2013). Potential cotton aphid, Aphis gossypii, population suppression by arthropod predators in upland cotton. Insect Science 20:778-788.

Steinkraus DC, Boys GO, Rosenheim JA (2002). Classical biological control of Aphis gossypii (homoptera: Aphididae) with Neozygites fresenii (Entomophthorales: Neozygitaceae) in California cotton. Biological Control 25:297-304.

Storer JR, Young S, Hardie J (1999). Three-dimensional analysis of aphid landing behavior in the laboratory and field. Physiological Entomology 24:271-277.

Straw NA, Williams DT, Green G (2011). Influence of sticky trap color and height above ground on capture of alate Elatobium abietinum (Hemiptera: Aphididae) in Sitka spruce plantations. Environmental Entomology 1:120-125.

Wang Z, Xu J, Wei H (2015). Spring frost following warm spell and its effect on the growth of the trees in spring. 16:195-201. (in Chinese with English abstract)

Wang L, Zhang S, Luo JY, Wang CY, Lv LM, Zhu XZ, Li CH, Cui JJ (2016). Identification of Aphis gossypii Glover (Hemiptera: Aphididae) biotypes from different host plants in North China. PLoS one 11:e0146345. 
Wei H, Hauer RJ, Chen G, Chen X, He X (2020). Growth, nutrient assimilation, and carbohydrate metabolism in Korean pine (Pinus koraiensis) seedlings in response to light spectra. Forests 11(1):44.

Wu KM, Guo YY (2003). Influence of Bacillus thuringiensis Berliner cotton planting on population dynamics of the cotton aphid, Aphis gossypii Glover, in Northern China. Environmental Entomology 32:312-318.

Ying QL, Kong Y, Jones C, Zheng YB (2020). Responses of yield and appearance quality of four Brassicaceae microgreens to varied blue light proportion in red and blue light-emitting diodes lighting. Scientia Horticulturae 259:108857.

Yokomi RK, Tang YQ (1995). Host preference and suitability of two Aphelinid parasitoids (Hym: Aphelinidae) for Aphid (Hom: Aphididae) on citrus. Journal of Economic Entomology 88:840-845.

OPEN ACCESS

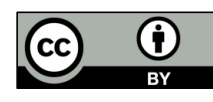

The journal offers free, immediate, and unrestricted access to peer-reviewed research and scholarly work. Users are allowed to read, download, copy, distribute, print, search, or link to the full texts of the articles, or use them for any other lawful purpose, without asking prior permission from the publisher or the author.

License - Papers published in Notulae Botanicae Horti Agrobotanici Cluj-Napoca are Open-Access, distributed under the terms and conditions of the Creative Commons Attribution (CC BY 4.0) License. (C) Articles by the authors; UASVM, Cluj-Napoca, Romania. The journal allows the author(s) to hold the copyright/to retain publishing rights without restriction. 